\title{
Degradation of hydrogen peroxide at the ocean's surface: the influence of the microbial community on the realized thermal niche of Prochlorococcus
}

\author{
Lanying $\mathrm{Ma}^{1}$, Benjamin C Calfee ${ }^{1}$, J Jeffrey Morris ${ }^{2}$, Zackary I Johnson ${ }^{3}$ and Erik R Zinser ${ }^{1}$ \\ ${ }^{1}$ Department of Microbiology, University of Tennessee, Knoxville, TN, USA; ${ }^{2}$ Department of Biology, \\ University of Alabama at Birmingham, Birmingham, AL, USA and ${ }^{3}$ Nicholas School of the Environment and \\ Biology Department, Duke University Marine Laboratory, Beaufort, NC, USA
}

\begin{abstract}
Prochlorococcus, the smallest and most abundant phytoplankter in the ocean, is highly sensitive to hydrogen peroxide $(\mathrm{HOOH})$, and co-occurring heterotrophs such as Alteromonas facilitate the growth of Prochlorococcus by scavenging HOOH. Temperature is also a major influence on Prochlorococcus abundance and distribution in the ocean, and studies in other photosynthetic organisms have shown that $\mathrm{HOOH}$ and temperature extremes can act together as synergistic stressors. To address potential synergistic effects of temperature and $\mathrm{HOOH}$ on Prochlorococcus growth, high- and low-temperatureadapted representative strains were cultured at ecologically relevant concentrations under a range of $\mathrm{HOOH}$ concentrations and temperatures. Higher concentrations of $\mathrm{HOOH}$ severely diminished the permissive temperature range for growth of both Prochlorococcus strains. At the permissive temperatures, the growth rates of both Prochlorococcus strains decreased as a function of $\mathrm{HOOH}$,

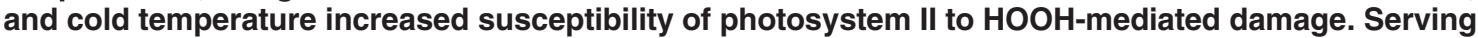
as a proxy for the natural community, co-cultured heterotrophic bacteria increased the Prochlorococcus growth rate under these temperatures, and expanded the permissive range of temperature for growth. These studies indicate that in the ocean, the cross-protective function of the microbial community may confer a fitness increase for Prochlorococcus at its temperature extremes, especially near the ocean surface where oxidative stress is highest. This interaction may play a substantial role in defining the realized thermal niche and habitat range of Prochlorococcus with respect to latitude. The ISME Journal (2018) 12, 473-484; doi:10.1038/ismej.2017.182; published online 31 October 2017
\end{abstract}

\section{Introduction}

Stress is a common state for microbes, and it is becoming clear that biological interactions can augment or ameliorate this condition. Apart from nutritional stress (Amin et al., 2012), microbemicrobe interactions can mediate relief from a variety of abiotic environmental stresses, in a process generally referred to as facilitation. Facilitation is a widely (Bertness and Callaway, 1994; Brooker and Callaghan, 1998; Callaway et al., 2002) though not universally (Maestre and Cortina, 2004) accepted principle in metazoan ecology, which posits that at environmental extremes positive interactions between organisms tend to dominate over negative ones (Callaway et al., 2002; Brooker et al., 2005). There are fewer investigations of facilitation for microbes, but examples include the bacterialmediated cross-protection of phytoplankton from

Correspondence: ER Zinser, Department of Microbiology, University of Tennessee, M409 WLS, Knoxville, TN 37996, USA.

E-mail: ezinser@utk.edu

Received 27 January 2017; revised 14 September 2017; accepted 22 September 2017; published online 31 October 2017 inorganic carbon limitation and oxygen toxicity (Chirac et al., 1985; Ma and Eaton, 1992). Bacteria can also improve the thermotolerance of phytoplankton; in the case of the green alga Chlamydomonas reinhardtii bacteria provide vitamin $\mathrm{B}_{12}$ that is required for the thermotolerant isozyme of a key metabolic reaction (Xie et al., 2013). Finally, microbes can also protect other microbes from oxidative stresses by the removal of the reactive oxygen species from the environment. Such beneficiaries include heterotrophic microbes (Ma and Eaton, 1992; Beliaev et al., 2014; Morris et al., 2014), Antarctic diatoms (Hunken et al., 2008) and, as we demonstrated in prior studies (Morris et al., 2008, 2011), the marine cyanobacterium Prochlorococcus.

Prochlorococcus is the smallest phytoplankter in the oligotrophic open ocean; they are also believed to be the most abundant photosynthetic autotroph on Earth (Partensky et al., 1999; Flombaum et al., 2013). Numerical success of Prochlorocccus in the nutrientpoor open ocean has been attributed to several evolutionary innovations, of which genome streamlining has been frequently cited (Strehl et al., 1999; Dufresne et al., 2005; Coleman and Chisholm, 2007; 
Scanlan et al., 2009). Streamlining can improve growth efficiency by reducing cellular nitrogen and/ or phosphorus quotas, but the loss of genes can also result in deficiencies that must be otherwise satisfied if the streamlined organism is to take advantage of the improved efficiency. Prior work by our group has identified one such deficiency of Prochlorococcus resulting from genome streamlining: a diminished oxidative stress response (Morris et al., 2011). Unlike most cyanobacteria and other aerobes, Prochlorococcus lacks the hydrogen peroxide (HOOH)-degrading enzyme catalase, and consequently is highly sensitive to this oxidant. The ecological consequence for this loss is severe, in that Prochlorococcus growth at the ocean surface depends on the ability of the cooccurring microbes to degrade $\mathrm{HOOH}$. The activity of the extant microbial community (Morris et al., 2016) maintains $\mathrm{HOOH}$ at concentrations permissive for Prochlorococcus growth (<200 nM) (Cooper et al., 1987; Miller and Kester, 1994; Hanson et al., 2001; Yuan and Shiller, 2001; Morris et al., 2011); in the absence of this community the $\mathrm{HOOH}$ concentrations in the sunlit mixed layer can rise to levels $(\geqslant 800 \mathrm{nM})$ that can kill all ecotypes of Prochlorococcus found in the mixed layer (Morris et al., 2011). Hence, in the evolutionary history of Prochlorococcus, it may have taken advantage of the $\mathrm{HOOH}$ degradation capacity of the community as a 'public good', which made its own catalase dispensible and subject to loss via a 'Black Queen’ evolutionary process (Morris et al., 2012).

In the natural world, multiple stresses can cooccur, and for photosynthetic microbes temperature stress is known to act synergistically with oxidative stress. Temperature extremes can generate excess reactive oxygen species (Smirnova et al., 2007), leading to oxidative stress (Lesser, 1996) and cell mortality (Davidson et al., 1996). In cyanobacteria, temperature extremes and $\mathrm{HOOH}$ both impact photosynthesis by interfering with a key step in the repair of damaged photosystem II (PSII). D1 is the reaction center chlorophyll-containing protein of PSII, and is rapidly damaged during photosynthetic electron flow. Rather than being repaired, damaged D1 is replaced, and both temperature and $\mathrm{HOOH}$ stress can interfere with the synthesis and/or postprocessing steps involved in this replacement (Ma and Eaton, 1992; Nishiyama et al., 2001, 2006; Kojima et al., 2007). Given the potential for synergistic effects of oxidative and thermal stresses on Prochlorococcus growth and photosynthesis, we hypothesized that (1) temperature extremes sensitize Prochlorococcus to $\mathrm{HOOH}$-mediated damage, and that (2) by reducing $\mathrm{HOOH}$ concentrations, the extant microbial community facilitates the survival and growth of Prochlorococcus at these temperature extremes.

While multiple ecotypes of Prochlorococcus have been identified, the water column is typically dominated numerically by one of two ecotypes, eMED4 or eMIT9312 (also referred to as HL-I and HLII, respectively (Rocap et al., 2002; Johnson et al.,
2006; Zwirglmaier et al., 2008). These high-light adapted ecotypes partition the surface ocean by latitude, with eMIT9312 dominating the low latitudes $\left(\sim \mathrm{N} 30^{\circ}-\mathrm{S} 30^{\circ}\right)$, and eMED4 the high latitudes north and south of the equator $\left(\sim 30^{\circ}-40^{\circ}\right)$ (Johnson et al., 2006). Temperature was identified as the key environmental variable correlating with abundance of these two ecotypes (Johnson et al., 2006; Chandler et al., 2016). Consistent with the field data, studies with non-axenic cultures of isolated strains confirmed that while both ecotypes share a common temperature optimum $\left(\sim 24^{\circ} \mathrm{C}\right)$, the eMED4 strains grew faster and at a broader range of temperatures below $\sim 19^{\circ} \mathrm{C}$, compared to the eMIT9312 strains, while the opposite held true for cultures grown above the optimum (Johnson et al., 2006). Collectively, these studies suggested that the different physiological responses to temperature play a major role in establishing the distribution patterns of these recently diverged lineages in nature. However, as the culture experiments were performed at high cell densities and in the presence of heterotrophic bacterial contaminants (Johnson et al., 2006), the influence of the microbial community on the temperature range of Prochlorococcus was unconstrained, but could be significant due to its impact on the concentration of $\mathrm{HOOH}$.

In this study we used low, ecologically relevant concentrations of representatives of the high- and low-temperature-adapted ecotypes of Prochlorococcus, grown in the presence or absence of a heterotrophic helper Alteromonas sp. EZ55, to directly test the hypothesis that $\mathrm{HOOH}$ acts synergistically with high or low temperatures to restrict growth. We show that $\mathrm{HOOH}$ is more deleterious to Prochlorococcus when growing at suboptimal temperatures, and that by elimination of $\mathrm{HOOH}$, the activity of the community facilitates the growth of Prochlorococcus at its temperature extremes and may expand its meridional range in the open ocean.

\section{Materials and methods}

Prochlorococcus strains and culture conditions

Axenic streptomycin-resistant derivatives of Prochlorococcus strains MIT9312 and MED4 (VOL 4 and VOL 7, respectively (Morris et al., 2011)) were used in this study. These strains, referred to hereafter as MIT9312 and MED4 for simplicity, were cultured in filtered artificial seawater AMP-J medium (Morris et al., 2008; Morris and Zinser, 2013) (per L, $28.1 \mathrm{~g}$ $\mathrm{NaCl}$, $6.9 \mathrm{~g} \mathrm{MgSO}_{4} \times 7 \mathrm{H}_{2} \mathrm{O}$, $5.49 \mathrm{~g} \mathrm{MgCl}_{2} \times 6 \mathrm{H}_{2} \mathrm{O}$, $0.67 \mathrm{~g} \mathrm{KCl} 1.47 \mathrm{~g} \mathrm{CaCl}_{2}, 0.504 \mathrm{~g} \mathrm{NaHCO}_{3}$, with $2 \mathrm{ml}$ $0.5 \mathrm{M}$ TAPS $\mathrm{pH} 8.0,1 \mathrm{ml} 0.4 \mathrm{M}\left(\mathrm{NH}_{4}\right)_{2} \mathrm{SO}_{4}, 2 \mathrm{ml}$ $0.025 \mathrm{M} \mathrm{NaH}_{2} \mathrm{PO}_{4}$, pH7.5, $100 \mu \mathrm{l} 10000$ X Pro99 Trace Metal Mix) with $40 \mu \mathrm{mol}$ quanta $\mathrm{m}^{-2} \mathrm{~s}^{-1}$ light on a 12:12 light:dark cycle using cool white fluorescent bulbs. Cultures were acclimated to the test temperature for at least three transfers (minimum 20 generations) at high cell concentration $\left(>10^{7}\right.$ 
cells $\mathrm{ml}^{-1}$ ), before inoculation at low cell concentration (30000 cells $\left.\mathrm{ml}^{-1}\right)$ for the assessment of temperature and $\mathrm{HOOH}$ impacts on growth. $\mathrm{HOOH}$ concentration was increased from basal levels in the medium (61-90 nм) where appropriate. Axenicity of Prochlorococcus cultures was monitored by purity test in YTSS and 1/10 ProAC heterotrophic growth media (Morris et al., 2008).

The heterotrophic bacterium Alteromonas sp. EZ55 was grown for $48 \mathrm{~h}$ in $10 \mathrm{ml}$ YTSS medium (Gonzalez and Moran, 1997) (per l, $4.0 \mathrm{~g}$ tryptone, $2.5 \mathrm{~g}$ yeast extract, $15 \mathrm{~g}$ sea salts, autoclaved) on a roller drum at $22^{\circ} \mathrm{C}$. Cells were then diluted 1:1000 into $10 \mathrm{ml}$ minimal acetate medium (per $200 \mathrm{ml}$, $150 \mathrm{ml}$ Pro99 (Morris et al., 2008), $50 \mathrm{ml} 18 \mathrm{M} \Omega \mathrm{H}_{2} \mathrm{O}$, $0.5 \%$ acetate, $100 \mu \mathrm{l} 2000 \mathrm{X}$ VA vitamin mix (Waterbury and Willey, 1988) and incubated for $24 \mathrm{~h}$ on the roller drum. Cells were harvested by centrifugation at $4500 \mathrm{~g}$ for $5 \mathrm{~min}$, washed twice with sterile AMP-J medium and resuspended in sterile AMP-J medium. Resuspended cells were inoculated into AMP-J at a concentration of about $10^{6}$ cells $\mathrm{ml}^{-1}$, and incubated for $24 \mathrm{~h}$ at the appropriate temperature to precondition the media before the Prochlorococcus cells were added. Altermonas sp. EZ55 cells were left in the media throughout the Prochlorococcus growth experiment.

Quantification of Prochlorococcus and Alteromonas sp. EZ55

Concentration of Prochlorococcus was measured by flow cytometry with the Guava EasyCyte 8HT cytometer (Millipore, Billerica, MA, USA), using an established method (Morris et al., 2011). Flow cytometric quantification of Alteromonas sp. EZ55 was performed following staining of the cells with SYBR green (Tripp et al., 2008). Viable count assays for Alteromonas sp. EZ55 were performed by serial dilutions of the culture on YTSS plates. Plates were incubated overnight at room temperature and colonies were counted.

\section{HOOH quantification and amendments to media}

The HOOH concentration in the medium and cultures was measured by an Orion L Microplate Luminometer (Titertek Instruments Inc, Berthold Detection Systems, Pforzheim, Germany) based on an established method using acridinium ester (Morris et al., 2011). Concentration of $\mathrm{HOOH}$ in the culture medium was adjusted as needed to 200,400 , or $800 \mathrm{nM}$, once the basal concentration of the AMP-J medium was determined. Rates of $\mathrm{HOOH}$ degradation $k_{\mathrm{HOOH}}$ were calculated as the slope of the regression of $\mathrm{HOOH}$ concentration over time, over at least 3 days.

Sodium pyruvate scavenging $\mathrm{HOOH}$

Final concentration of $1 \mathrm{~mm}$ sodium pyruvate (Sigma-Aldrich, St Louis, MO, USA) was used as a direct scavenger of $\mathrm{HOOH}$ in the medium (Giandomenico et al., 1997; Kao and Fink, 2010). Sodium pyruvate was added to the medium at the same time as Alteromonas sp. EZ55 was added, which was $24 \mathrm{~h}$ before the addition of Prochlorococcus cultures. $1 \mathrm{~mm}$ sodium pyruvate has been shown to have the most similar HOOH scavenging ability to Alteromonas sp. EZ55 (Supplementary Figures S1 and S2); by $24 \mathrm{~h}$ the concentration fell below the limit of detection (10 nм) (Supplementary Figure S1).

\section{Measurement of photosynthesis parameters $\mathrm{FV} / \mathrm{Fm}$ with lincomycin}

Fast Induction and Relaxation (FIRe) fluorometer (Satlantic, Halifax, Nova Scotia, Canada) was used to measure the photophysiological parameters (initial fluorescence, Fo; maximal fluorescence, Fm; and variable fluorescence, Fv) by established methods (Johnson, 2004). Lincomycin (Sigma-Aldrich) was dissolved in water and added into tubes with a final concentration of $500 \mu \mathrm{g} \mathrm{ml}^{-1}$. Higher concentrations had the same impact on Fv/Fm in trial studies (data not shown), providing confidence that maximum inhibition was achieved at this concentration. Flow cytometry verified that neither lincomycin nor high (800 nM) $\mathrm{HOOH}$ impacted cell counts over the $8 \mathrm{~h}$ incubation at $24{ }^{\circ} \mathrm{C}$ : the ratio of the change in cell number $\left(\mathrm{T}_{0 \mathrm{~h}} / \mathrm{T}_{8 \mathrm{~h}}\right)$ for the lincomycin or high $\mathrm{HOOH}$ treatment versus no lincomycin, low (90 nM) HOOH control was 1.07 or 1.16 for MIT9312, and 1.22 or 1.22 for MED4, respectively.

\section{Modeling of potential effect of $\mathrm{HOOH}$ to the distribution of Prochlorococcus}

The potential range compression of surface communities of Prochlorococcus in the global ocean due to synergistic $\mathrm{HOOH}$ and temperature stressors was estimated by using an annual composite (Level 3 processing) surface temperature from 2013 quantified at $4 \mathrm{~km}$ resolution using the NASA Aqua MODIS $4 \mu$ sensor. For the base case (no HOOH effect), Prochlorococcus is assumed to be present at all temperatures greater than $10^{\circ} \mathrm{C}$, while at $400 \mathrm{~nm}$ $\mathrm{HOOH}$ Prochlorococcus is only found between 22 and $24^{\circ} \mathrm{C}$.

\section{Results}

Growth of the high-temperature-adapted Prochlorococcus strain MIT9312 at different temperatures under oxidative stress

Prior work with dense, non-axenic cultures indicated strain MIT9312, of the high-temperatureadapted eMIT9312 (HL-II) ecotype, had a growth optimum at $24^{\circ} \mathrm{C}$ (Johnson et al., 2006), and we confirmed this optimum for axenic, ecologically relevant concentrations (inoculum $<10^{5} \mathrm{cells} \mathrm{ml}^{-1}$ ) (Supplementary Figure S3). At $24^{\circ} \mathrm{C}$, $800 \mathrm{~nm} \mathrm{HOOH}$ is lethal to strains of all ecotypes of Prochlorococcus 


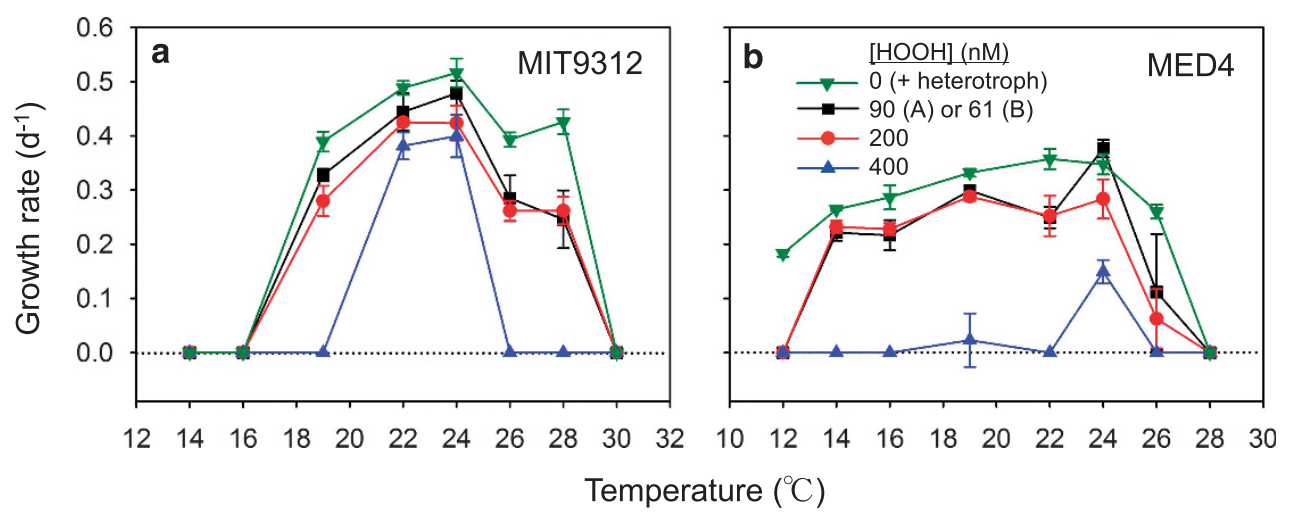

Figure 1 Growth of ecologically relevant concentrations of MIT9312 (a) and MED4 (b) at different temperatures and exogenous HOOH concentrations. Cells from temperature-acclimated dense $\left(>10^{7}\right.$ cells $\left.\mathrm{ml}^{-1}\right)$ mid-log cultures were inoculated into media containing ambient (90 or $61 \mathrm{~nm}$ for MIT9312 or MED4, respectively) or elevated (200 or $400 \mathrm{nM}$ ) HOOH, or in media pre-inoculated with the heterotroph Alteromonas sp. EZ55 (around $0 \mathrm{~nm} \mathrm{HOOH).} \mathrm{Values} \mathrm{on} \mathrm{the} \mathrm{black} \mathrm{dotted} \mathrm{line} \mathrm{denotes} \mathrm{zero} \mathrm{or} \mathrm{negative} \mathrm{net} \mathrm{growth} \mathrm{over} \mathrm{the}$ incubation period. See Supplementary Figure S4 for plots of calculated negative growth rates. Error bars denote the standard deviation for three biological replicates; see Supplementary Tables S1 and S2 for statistical analysis of the data.

found in the mixed layer (Morris et al., 2011), but concentrations below this value (90-400 nM) had minimal impact on growth of MIT9312 (Morris et al., 2011, and Figure 1a). Results at $22^{\circ} \mathrm{C}$ were similar to $24^{\circ} \mathrm{C}$, but for other temperatures within the growth range of this strain, sensitivity to $\mathrm{HOOH}$ was significantly increased (Figure 1a, Supplementary Table S1). At the unadjusted medium $\mathrm{HOOH}$ concentrations $(90 \mathrm{~nm})$, the permissive temperature range was $19-28^{\circ} \mathrm{C}$, similar to the prior study with dense non-axenic cultures (Johnson et al., 2006) (Supplementary Figure S3). Increases to $200 \mathrm{~nm}$ $\mathrm{HOOH}$ did not significantly impact growth over this temperature range relative to $90 \mathrm{~nm}$ (Supplementary Table S1), although the overall trend was a slight decrease in rate (Figure 1a). At $24^{\circ} \mathrm{C}$ (its growth optimimum) and $22^{\circ} \mathrm{C}$, MIT9312 growth in $400 \mathrm{~nm}$ HOOH was significantly slower than 90 nм $(P<0.05)$ but not $200 \mathrm{~nm}(P>0.05)$ (Figure 1a, Supplementary Table S1). Critically, $400 \mathrm{~nm} \mathrm{HOOH}$ was lethal at all other temperatures tested (Figure 1a). At 19, 26 and $28^{\circ} \mathrm{C}$, a slow but steady decline in cell concentrations was observed over several days, whereas at the more extreme temperatures tested $\left(14,16,30^{\circ} \mathrm{C}\right)$, a more dramatic effect was observed (Supplementary Figure S4). At these extremes, no cells could be detected after only $24 \mathrm{~h}$ post-inoculation, indicating that the cells rapidly lost chlorophyll-based red fluorescence and/or cell integrity (see Discussion).

Prochlorococcus lacks catalase but can, at slow rates, remove $\mathrm{HOOH}$ from the medium (Morris et al., 2011). While the degradation rates are too slow to dramatically improve tolerance to $\mathrm{HOOH}$ at ecologically relevant cell concentrations (Morris et al., 2011), it was nonetheless notable that the rates of HOOH degradation by MIT9312 varied as a function of temperature and initial concentration of $\mathrm{HOOH}$ (Supplementary Figure S5). There were significant effects of both temperature and initial $\mathrm{HOOH}$ concentration on the rate of $\mathrm{HOOH}$ degradation
$\left(k_{\mathrm{HOOH}}\right)$ in axenic cultures. $k_{\mathrm{HOOH}}$ was significantly higher at $24^{\circ} \mathrm{C}$ than at any other tested temperature (Supplementary Figure S5A), coinciding with the optimum growth temperature for this strain (Figure 1a). The influence of initial $\mathrm{HOOH}$ concentration was negative and significantly linear $(P=0.002)$, with $k_{\mathrm{HOOH}}$ decreasing by about $0.0004 \mathrm{~d}^{-1}$ for each increase of $1 \mathrm{~nm}$ initial $\mathrm{HOOH}$ (Supplementary Figure S5B).

In a prior study we described how heterotrophic bacteria can protect Prochlorococcus from $\mathrm{HOOH}-$ mediated oxidative damage by removing $\mathrm{HOOH}$ from the medium (Morris et al., 2011). As this earlier work was performed exclusively at $24^{\circ} \mathrm{C}$, we investigated if this helping phenomenon occurs throughout the thermal range of Prochlorococcus, and whether co-culture with helpers might expand the permissive range for growth. The helper heterotroph Alteromonas sp. EZ55 was able to rapidly remove $\mathrm{HOOH}$ to below detectable limits at both high $\left(28^{\circ} \mathrm{C}\right)$ and low $\left(19^{\circ} \mathrm{C}\right)$ temperatures (Supplementary Figure S2), and thus could serve to help Prochlorococcus throughout its thermal growth range. While no range expansion was observed for MIT9312, significantly higher $(P<0.05)$ rates of growth were observed at 26 and $28^{\circ} \mathrm{C}$ in media pre-conditioned by the presence of Altermonas sp. EZ55, relative to the untreated control (Figure 1a, Supplementary Table S1). Similar results were found at $19^{\circ} \mathrm{C}$ although they were only marginally significant $(P=0.052)$ (Figure 1a, Supplementary Table S1). Alteromonas sp. EZ55-treated media had undetectable levels of $\mathrm{HOOH}$ (data not shown; limit of detection $=10 \mathrm{~nm}$ ), whereas the control cultures had low but detectable $\mathrm{HOOH}$ ( $90 \mathrm{~nm}$ ). The growth rate in Alteromonas sp. EZ55-treated media was significantly higher $(P<0.05)$ than growth in 200 or $400 \mathrm{~nm}$ $\mathrm{HOOH}$ at all temperatures (Figure 1a, Supplementary Table S1). These data suggest that even $90 \mathrm{~nm} \mathrm{HOOH}$ can harm Prochlorococcus, especially at elevated 
temperature, consistent with the observation of a linear relationship between $k_{\mathrm{HOOH}}$ and initial $\mathrm{HOOH}$ concentration (Supplementary Figure S5B), and that this harm can be negated by the action of co-cultured heterotrophic bacteria.

To assess if the enhancing effect of the helper at suboptimal temperatures was due strictly to its $\mathrm{HOOH}$ degrading capacity, these results were compared to those using an alternative, abiotic means of removing $\mathrm{HOOH}$ from the medium. Pyruvate effectively scavenges $\mathrm{HOOH}$ (Mizunoe et al., 1999; Long and Halliwell, 2009; Coe et al., 2016) (Supplementary Figure S1) by an abiotic chemical reaction (Giandomenico et al., 1997; Kao and Fink, 2010); such treatments have proven valuable in the cultivation of other microbes (Troxell et al., 2014; Kim et al., 2016) and for the prolonged survival of Prochlorococcus in darkness (Coe et al., 2016). At $28^{\circ} \mathrm{C}$, the growth rate of MIT9312 in pyruvatetreated medium $(\sim 0 \mathrm{nM} \mathrm{HOOH})$ was significantly higher $(P=0.0058)$ than in the untreated control (90 nM) (Figure 2). Thus, by different chemistries the two treatments employed-live bacteria with enzymes and pyruvate-effectively decreased $\mathrm{HOOH}$ below detection, and both lead to an enhancement of MIT9312 growth post-treatment. These data support the prior conclusion that even $90 \mathrm{~nm} \mathrm{HOOH}$ can negatively impact Prochlorococcus growth. Importantly, however, cultures given pretreatment with a heterotrophic helper grew faster than those pre-treated with pyruvate (Figure 2). At a less extreme temperature of $26^{\circ} \mathrm{C}$ the trends were similar but not significant (Figure 2).

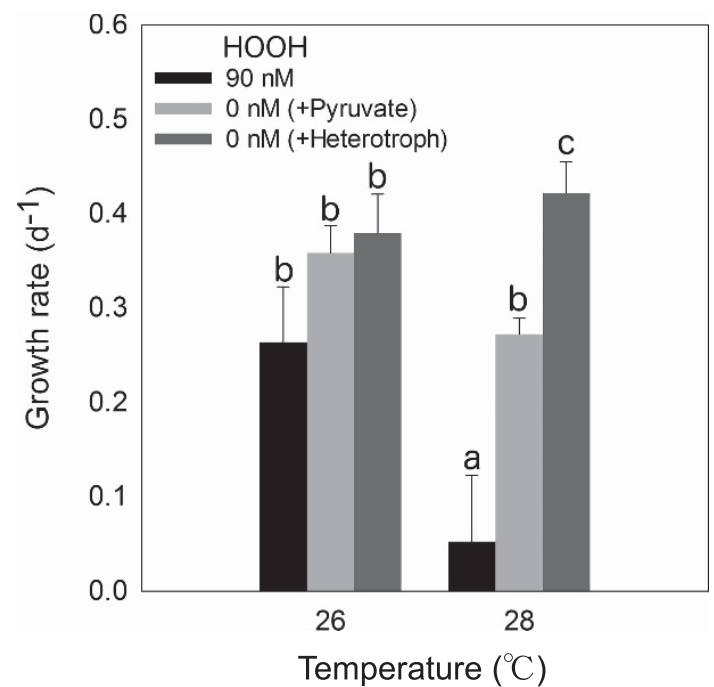

Figure 2 The effect of pyruvate as an alternative $\mathrm{HOOH}$ scavenger. Growth rates of MIT9312 in ambient (90 nм HOOH) medium or medium pre-treated with pyruvate or Alteromonas sp. EZ55 (both: $0 \mathrm{~nm} \mathrm{HOOH}$ ) at 26 or $28^{\circ} \mathrm{C}$. Letters above bars denote groups of treatments whose values were not statistically different $(P>0.05)$. Error bars denote the standard deviation for three biological replicates.
Growth of the low-temperature-adapted strain MED4

under temperature and oxidative stresses

Strain MED4 of the low-temperature-adapted ecotype eMED4 (HL-I) exhibited similar growth responses to $\mathrm{HOOH}$, temperature, and helper treatments as the high -temperature-adapted MIT9312, although some strain-strain differences were noted (Figure 1b, Supplementary Table S2). MED4 cultures grew between 12 and $26^{\circ} \mathrm{C}$, which was cold-shifted relative to MIT9312 (16 to $28^{\circ} \mathrm{C}$ ) and its temperature versus growth rate profile was similar to that reported for dense non-axenic cultures (Johnson et al., 2006) (Supplementary Figure S3). Importantly, dilute MED4 could only grow at $12^{\circ} \mathrm{C}$ when in the presence of heterotrophs (Figure 1b), showing that heterotrophic bacteria can expand the permissive temperature range for this strain of Prochlorococcus, and also suggesting that even $61 \mathrm{~nm} \mathrm{HOOH}$ (the unadjusted medium concentration) can be lethal to Prochlorococcus under certain conditions. Like MIT9312, growth of pure cultures of MED4 was highly restricted at $400 \mathrm{~nm} \mathrm{HOOH}$, in this case occurring only at the growth optimum, $24^{\circ} \mathrm{C}$, and at a significantly lower rate $(P<0.001)$ than at ambient $\mathrm{HOOH}$ (Figure 1b). The kinetics of cell loss at the non-permissive temperatures was slow enough that rates of cell loss could be calculated, except at $12^{\circ} \mathrm{C}$, when all cells (without helpers) disappeared by $24 \mathrm{~h}$ (Supplementary Figure S4). In general, the rate of cell loss at the non-permissive temperatures increased as a function of $\mathrm{HOOH}$ and extremity of temperature (Supplementary Figure S4). Pretreatment with heterotroph helpers increased the growth rate of MED4 at $26^{\circ} \mathrm{C}$, and decreased the death rate at $28^{\circ} \mathrm{C}$ (Figure $1 \mathrm{~b}$ ), showing a similar trend to MIT9312 where the helping effect was maximal at the temperature extremes. Unlike MIT9312, MED4 did not show faster $\mathrm{HOOH}$ decay at its $24^{\circ} \mathrm{C}$ growth optimum relative to other temperatures (Supplementary Figure S5C), but like MIT9312 did show a negative and significantly linear $(P=0.0002)$ influence of initial $\mathrm{HOOH}$ concentration, with $k_{\mathrm{HOOH}}$ decreasing by about $0.00023 \mathrm{~d}^{-1}$ for each increase of $1 \mathrm{~nm}$ initial $\mathrm{HOOH}$ (Supplementary Figure S5D).

Impacts of temperature and $\mathrm{HOOH}$ on photosynthetic efficiency

Our prior work on Prochlorococcus at $24^{\circ} \mathrm{C}$ showed that $\mathrm{HOOH}$ can strongly diminish Fv/Fm, a fluorescence-based proxy for PSII efficiency and health (Morris et al., 2011). To assess the combined contributions of temperature and oxidative stress on Prochlorococcus PSII health, we quantified Fv/Fm under various temperature and $\mathrm{HOOH}$ conditions. We first examined the influence of temperature on Fv/Fm during growth, keeping the $\mathrm{HOOH}$ at low, ambient concentrations (90 nM). A previous study of MED4 found a small but significant increase in Fv/ Fm over the $16-24^{\circ} \mathrm{C}$ range (Kulk et al., 2012), and 
our cultures of this strain grown with $90 \mathrm{~nm} \mathrm{HOOH}$ showed similar trends (Supplementary Figure S6). Growth at more extreme 14 or $26^{\circ} \mathrm{C}$ temperatures had minimal influence on Fv/Fm, but a shift to the lethal $12{ }^{\circ} \mathrm{C}$ temperature resulted in a significant decline (Supplementary Figure S6). Similarly, MIT9312 maintained an $\mathrm{Fv} / \mathrm{Fm}$ value of approximately 0.6 for the $19-28^{\circ} \mathrm{C}$ range, but growth at $16{ }^{\circ} \mathrm{C}$, its low temperature lethal limit, resulted in a significant decline of $\mathrm{Fv} / \mathrm{Fm}$ (Supplementary Figure S6).

To assess the combined influence of temperature and oxidative stress, we challenged the temperatureacclimated cultures with exposure to elevated concentrations of $\mathrm{HOOH}$. As Prochlorococcus can potentially mitigate damage from $\mathrm{HOOH}$ over longer incubations via a slow depletion of external $\mathrm{HOOH}$ (Supplementary Figure S5), we performed our analysis during short incubations (up to $8 \mathrm{~h}$ ). Exposure to ambient concentrations of $\mathrm{HOOH}$ (90 nM) did not lead to decreases of Fv/Fm over the $8 \mathrm{~h}$ incubation (Supplementary Figures S7 and S8), nor did exposure to $400 \mathrm{~nm} \mathrm{HOOH} \mathrm{(Supplementary}$ Tables S5 and S6). However, exposure to $800 \mathrm{~nm}$ $\mathrm{HOOH}$-the lethal concentration at $24^{\circ} \mathrm{C}$ (Morris et al., 2011)-resulted in declines of $\mathrm{Fv} / \mathrm{Fm}$ that varied by temperature and strain (Figure 3). The

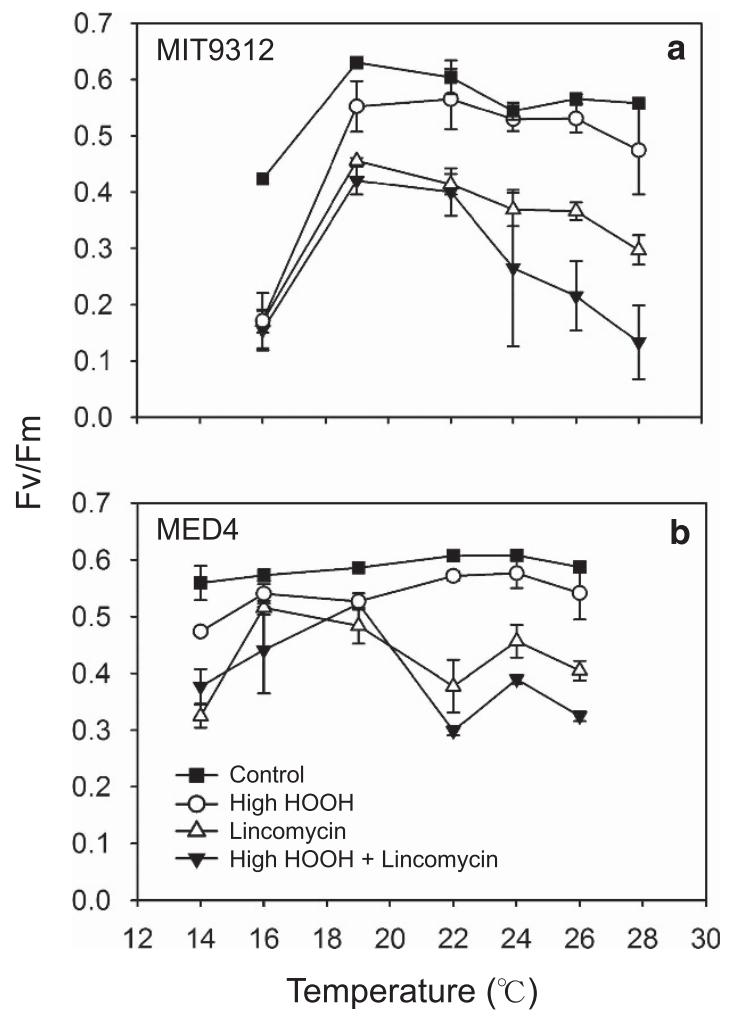

Figure 3 Photosynthetic efficiency of MIT9312 (a) or MED4 (b) as a function of temperature, $\mathrm{HOOH}$ and translation inhibitor lincomycin. Cultures grown at high cell density were diluted to low density and incubated for $8 \mathrm{~h}$ in the presence of $800 \mathrm{~nm} \mathrm{HOOH}$ (high $\mathrm{HOOH}$ ), lincomycin, both, or neither (control) treatment. Fv/ Fm values after the $8 \mathrm{~h}$ incubation are reported. Error bars denote the standard deviation for three biological replicates. response was significant ( $t$-test, $P<0.05)$ and most pronounced at the low temperature extreme for both strains: 16 and $14{ }^{\circ} \mathrm{C}$ for MIT9312 and MED4, respectively (Figure 3, Supplementary Tables S3 and S4). While not statistically significant (Supplementary Table S3), the overall trend for MIT9312 over the rest of the temperature range was a decrease in $\mathrm{Fv} / \mathrm{Fm}$ with the 800 nM exposure versus the ambient low $\mathrm{HOOH}$ concentration (Figure 3). A similar trend was observed for MED4 (Figure 3), except that the differences were significant at 14, 16 and and $19^{\circ} \mathrm{C}$ (Supplementary Table S4).

The combined influences of (low) temperature and (high) $\mathrm{HOOH}$ on PSII health described above are consistent with the findings in other studies (Murata et al., 2007; Takahashi et al., 2009) that these multiple stressors prevent PSII repair by blocking synthesis and/or processing of nascent D1 protein. To calibrate the extent to which temperature and $\mathrm{HOOH}$ may block this repair, we compared their impacts to that of lincomycin, an effective inhibitor of translation in Prochlorococcus and Synechococcus (Six et al., 2007). For MIT9312, exposure to lincomycin or $\mathrm{HOOH}$ at $16^{\circ} \mathrm{C}$ led to the same dramatic decline of $\mathrm{Fv} / \mathrm{Fm}$ over the $8 \mathrm{~h}$ incubation (Figure 3, Supplementary Figure S7). At higher temperatures, the decline in $\mathrm{Fv} / \mathrm{Fm}$ for lincomycin treatment exceeded that of high $\mathrm{HOOH}$ (Figure 3 and Supplementary Table S3). For MED4, significant differences in $\mathrm{Fv} / \mathrm{Fm}$ with high $\mathrm{HOOH}$ exposure versus lincomycin treatment were found at 14, 22, 24 and $26^{\circ} \mathrm{C}$, but not at 16 and $19^{\circ} \mathrm{C}$ (Figure 3, Supplementary Figure S8, Supplementary Table S4). Notably, for both strains at multiple temperatures, the degree to which Fv/Fm dropped when cells were challenged with both lincomycin and high $\mathrm{HOOH}$ exceeded that for either treatment individually (Figure 3). This higher drop in the combined treatment was significant at 19,26 and $28^{\circ} \mathrm{C}$ for MIT9312, and all temperatures examined except $19^{\circ} \mathrm{C}$ for MED4 (Supplementary Tables S3 and S4).

\section{Discussion}

The results of this study support the hypothesis that growth at temperature extremes heightens the sensitivity of Prochlorococcus to hydrogen peroxide. Three major interactive effects were observed between temperature and $\mathrm{HOOH}$. First, the range of permissive temperature decreases with elevated $\mathrm{HOOH}$. Even as little as $61 \mathrm{~nm} \mathrm{HOOH}$ was sufficient to constrain the permissive temperature range for growth, as evidenced by MED4 at $12^{\circ} \mathrm{C}$, while higher concentrations (400 nM) constrained the permissive temperature to the growth optimum or just below. Second, within the permissive temperature range, growth rate tended to decrease as a function of $\mathrm{HOOH}$ concentration through the assayed range of 0-400 nм. Third, for the $400 \mathrm{~nm}$ treatment, the death rate (measured as the loss of detectable cells) at the 
lethal temperatures increased with increasing divergence from optimal temperature $\left(24^{\circ} \mathrm{C}\right)$. These three effects were observed in both MIT9312 and MED4, chosen as representatives of the two numerically dominant ecotypes of Prochlorococcus in the ocean (Rocap et al., 2002), and at ecologically relevant concentrations of cells and $\mathrm{HOOH}$. The final major conclusion of this study is that this heightened sensitivity to temperature is tempered significantly by the presence of $\mathrm{HOOH}$-consuming bacteria. With all due caution in extending results from culturebased studies into natural populations, these results demonstrate that temperature extremes and high $\mathrm{HOOH}$ act as synergistic stresses on Prochlorococcus, and suggest that Prochlorococcus is more dependent on the microbial community at its temperature extremes.

Damage mechanisms of oxidative and thermal stress in Prochlorococcus

Photosynthetic efficiency $(\mathrm{Fv} / \mathrm{Fm})$ is used as a diagnostic of photosynthetic health of natural phytoplankton communities, including the open ocean where Prochlorococcus contributes significantly to chlorophyll and primary production (Behrenfeld et al., 2006; Johnson et al., 2010; Ryan-Keogh et al., 2013; Wilhelm et al., 2013; Lin et al., 2016). Prior studies showed that as a single stressor, temperature had only a minor influence on photosynthetic efficiency of Prochlorococcus (Fu et al., 2007; Kulk et al., 2012). Our results are in general agreement, but we also add that $\mathrm{Fv} / \mathrm{Fm}$ drops significantly $(P=0.0001)$ at extreme low temperature, as observed in both strains at their respective temperature limit. While temperature alone may not impact photosynthetic efficiency in Prochlorococcus, except at the aforementioned cold-temperature limit, we found that it sensitizes this genus to co-occurring oxidative stress, to which it is already highly sensitive even under optimal temperature (Morris et al., 2011; Mella-Flores et al., 2012). This was evident in the $\mathrm{Fv} / \mathrm{Fm}$ measurements for 8 -h exposures to $800 \mathrm{~nm}$ $\mathrm{HOOH}$; lower concentrations did not show any effects, however. The relatively short timeframe was chosen to limit the ability of Prochlorococcus to influence the $\mathrm{HOOH}$ concentration during the exposure (Morris et al., 2011, and Supplementary Figure S5) and thus mitigate the threat to its photosystems (it was also chosen to minimize the influence of global transcription arrest in the Fv/Fm assays involving lincomycin treatments, discussed below). We suspect that the trends found for the acute $800 \mathrm{~nm} \mathrm{HOOH}$ exposures will reflect those of chronic exposures to lower concentrations of $\mathrm{HOOH}$, and future studies, where $\mathrm{HOOH}$ concentrations can be effectively stabilized over days of Prochlorococcus growth, should be performed to test this hypothesis.

The increased sensitivity to $\mathrm{HOOH}$ at the temperature extremes is partially explained by a decrease in the innate capacity of Prochlorococcus to degrade $\mathrm{HOOH}$ (Supplementary Figure S5). Notably, growth at low temperature also sensitizes Prochlorococcus strain MED4 to excessive ultraviolet and photosynthetically available radiation (Neale and Thomas, 2017), likely through generation of singlet oxygen (Vass, 2011), an reactive oxygen species agent to which photosystem II of Prochlorococcus is especially vulnerable (Murphy et al., 2017). Collectively, these observations suggest that the impacts of oxidative stressors on the photosynthetic health and activity of Prochlorococcus depend on the temperature at which they are growing in the ocean, which can vary widely by latitude and season.

In freshwater cyanobacteria, $\mathrm{HOOH}$ and temperature block D1 replacement at translation and posttranslation stages, respectively (Ma and Eaton, 1992; Nishiyama et al., 2001, 2006; Chaloub et al., 2003), and our results suggest similar blocks may be occurring in Prochlorococcus that contribute to the decline in photosynthetic efficiency of PSII. Comparisons to lincomycin-treated cultures indicated that the combined $\mathrm{HOOH}$ and temperature treatments may only partially block D1 replacement (except at the low-temperature limit) (Figure 3). However, although D1 is the most highly turned over protein and thus most susceptible to translation inhibition by lincomycin, the inability to synthesize other proteins over the $8 \mathrm{~h}$ incubation may have also contributed to the loss in Fv/Fm of the lincomycintreated cultures. Thus, further investigation of D1 translation and post-translational processing is warranted to assess the full extent of the block by $\mathrm{HOOH}$ and temperature. With this caveat in mind, we noted a curious result: the combination of high $\mathrm{HOOH}$ and lincomycin could diminish Fv/Fm more than lincomycin alone (Figure 3). This suggests that $\mathrm{HOOH}$ may have additional impacts than D1 replacement (and translation, generally). These non-mutually exclusive mechanisms may include damaging D1 directly (Vass et al., 1992; Keren et al., 1997), or electron carriers downstream of PSII (Morris et al., 2011), or the diunsaturated fatty acids present in Prochlorococcus (Biller et al., 2014) that compose the photosynthetic membranes.

The role of helper bacteria in protecting Prochlorococcus from interactive thermal and oxidative stresses

In prior work we demonstrated that co-cultured bacteria can protect Prochlorococcus from oxidative stress (Morris et al., 2008, 2011), and suggested that this beneficial interaction contributes to the evolutionary history (Morris et al., 2012) and ecological success (Morris et al., 2011) of this cyanobacterial genus. This work confirms that bacteria can protect Prochlorococcus from oxidative stress, and further demonstrates that this interaction can facilitate improved responses to temperature stress. This was 
perhaps most evident in MED4 growing at its cold limit: this strain was unable to grow at all at $12^{\circ} \mathrm{C}$ unless heterotrophic bacteria were present. In addition to expanding the permissive range of MED4, the helper also improved the growth rate of both strains within their permissive range. At high temperatures, even 60-90 nM HOOH was sufficient to slow the growth of Prochlorococcus, relative to $0 \mathrm{~nm} \mathrm{HOOH}$ (Figures 1 and 2). As such concentrations can be found in surface waters at these temperatures, even in the presence of $\mathrm{HOOH}$-degrading community (Cooper et al., 1987; Miller and Kester, 1994; Hanson et al., 2001; Yuan and Shiller, 2001; Morris et al., 2011), this indicates that $\mathrm{HOOH}$ may limit growth under these conditions, and suggests that the community may not perfectly protect Prochlorococcus under all situations in the natural world. Another benefit of the heterotrophic helpers was observed for MED4 at lethal high temperatures, where these helpers slowed the death kinetics of MED4 relative to the unamended control. This latter effect may be important for Prochlorococcus survival during acute exposures to lethal concentrations of $\mathrm{HOOH}$, which can occur during rainfall events (Cooper et al., 1987; Hanson et al., 2001).

There are several means by which one species can protect another from thermal stress, including shading (Bertness et al., 1999; Maestre et al., 2003; Bulleri, 2009) and provision of a co-factor for a heat-resistant isozyme that catalyzes an essential reaction in the beneficiary (Xie et al., 2013). The findings in this study are consistent with a third mechanism of thermal cross-protection: elimination of co-occurring oxidative stress. Stresses often cooccur in nature, and the interactive deleterious effects of high reactive oxygen species and temperature extremes have been well described in both photoautotrophic (Wise, 1995; Lesser, 1996; Thomas et al., 1999; Kocsy et al., 2001; Kranner et al., 2005; Almeselmani et al., 2006; Allakhverdiev et al., 2008) and heterotrophic (Davidson et al., 1996; Kranner et al., 2005; Chen et al., 2013) systems. Lichens (Kranner et al., 2005), anemones (Richier et al., 2005) and terrestrial plants (Redman et al., 2002) have all exhibited better responses to temperature stress when cross-protected by microbes from oxidative stress, and our results suggest that Prochlorococcus can be added to this list.

That pyruvate was able to help Prochlorococcus grow at higher temperatures, but not to the extent that live heterotrophic bacteria can, suggests that the bacteria are providing thermal benefits in addition to removal of $\mathrm{HOOH}$. Live Alteromonas helpers similarly outperformed pyruvate in improving the survival of Prochlorococcus in extended darkness (Coe et al., 2016). The lower growth rate in the pyruvateversus helper-treated media could be a negative consequence of a high concentration of pyruvate on Prochlorococcus growth. We believe this to be unlikely, however, as the growth rates of MIT9312 and MED4 at $24^{\circ} \mathrm{C}$, a temperature where the $\mathrm{HOOH}$ - consuming helper does not improve growth (Figure 1), are not decreased by the addition of pyruvate; pyruvate-treated cells grow as fast as helper-treated or un-treated cells (Supplementary Figure S9). Thus, the ability of Alteromonas to protect Prochlorococcus from diverse stressors is not completely explained by the removal of $\mathrm{HOOH}$ from culture media. In our earlier work we were able to rule out the importance of facilitation phenotypes found in other algae:helper systems (for example, metabolisms that deplete oxygen, replenish inorganic carbon, stabilize $\mathrm{pH}$, and/or provide an essential vitamin or other growth factor (Schiefer and Caldwell, 1982; Chirac et al., 1985; KeshtacherLiebson et al., 1995; Mouget et al., 1995; Croft et al., 2005; Geng and Belas, 2010; Xie et al., 2013)). However, those studies were performed at optimal temperature (Morris et al., 2011), and might be important for Prochlorococcus growth at temperature extremes or under other mixed stress regimes, and should be addressed in future studies.

\section{Ecological implications}

The meridional range for Prochlorococcus in the oligotrophic ocean is approximately $\mathrm{N} 40^{\circ}-\mathrm{S} 40^{\circ}$; survival and growth at higher latitudes are restricted by temperature (Johnson et al., 2006; Flombaum et al., 2013). Within the permissive range for Prochlorococcus, the concentration of $\mathrm{HOOH}$ in the open ocean mixed layer varies but rarely exceeds $100 \mathrm{~nm}$, except during rainfall events (Cooper et al., 1987; Miller and Kester, 1994; Hanson et al., 2001; Yuan and Shiller, 2001; Morris et al., 2011). The microbial community maintains this concentration at this low value; in absence of microbes the $\mathrm{HOOH}$ concentration exceeds the lethal limit for all known Prochlorococcus ecotypes (mean daily accumulation of $800 \mathrm{~nm}$ ) (Morris et al., 2011). By reporting the maximum growth rate for either MED4 or MIT9312 as a proxy for the growth performance of Prochlorococcus as a genus, we note a striking observation (Figure 4a). While the ability of the microbial community to maintain the concentration of $\mathrm{HOOH}$ below $800 \mathrm{~nm}$ facilitates Prochlorococcus growth at or near its temperature optimum, the ability of the community to maintain $\mathrm{HOOH}$ below $400 \mathrm{~nm}$ is essential for growth of this genus at all other temperatures.

Placing this physiolgical information in a global ecological context, we see that the ability of the community to lower the $\mathrm{HOOH}$ concentration has a dramatic influence on the oceanic abundance and distribution of Prochlorococcus. Temperature (Figure 4b) sets the high latitude limits for Prochlorococcus in the open ocean surface mixed layer in the presence of a mixed microbial community that maintains the $\mathrm{HOOH}$ concentration below $200 \mathrm{~nm}$ (Figure 4c). In total absence of the community, the $\mathrm{HOOH}$ concentration reaches a mean $800 \mathrm{~nm}$ (Morris et al., 2011), which would eliminate 
a
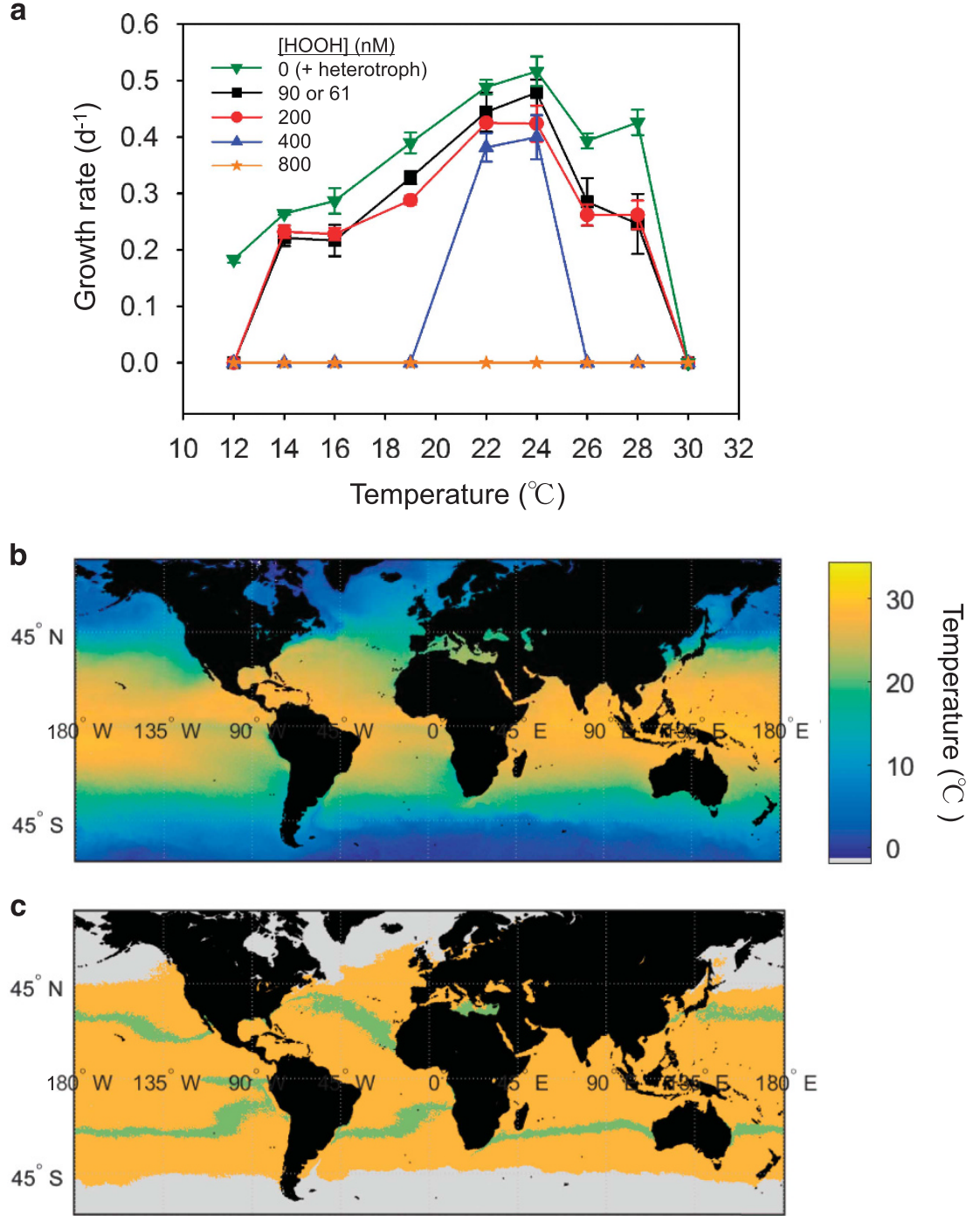

Figure 4 Genus-level relationships between Prochlorococcus growth and oceanic distribution as a function of temperature and HOOH. (a) Values were taken as the maximum growth rate for MED4 or MIT9312, which ever was highest under the given condition. The growth rates of Prochlorococcus with $800 \mathrm{~nm} \mathrm{HOOH}$ were set to zero, based on prior studies at the optimal temperature, $24{ }^{\circ} \mathrm{C}$ (Morris et al., 2011). (b) False-color image of the 2013 yearly composite of sea surface temperature in the oceans. (c) Sea surface distributions for Prochlorococcus under natural (non-axenic) conditions (yellow + green) and under hypothetical conditions where the concentration of $\mathrm{HOOH}$ was elevated to $400 \mathrm{~nm}$ (green). See Discussion for details.

Prochlorococcus from the global mixed layer entirely. If the community was only half as effective as it currently is, resulting in a $400 \mathrm{~nm}$ standing stock of $\mathrm{HOOH}$, the Prochlorococcus habitat range in the surface mixed layer $\left(3.04 \times 10^{7} \mathrm{~km}^{2}\right)$ would be only $11 \%$ as large as it is currently, and would occur in isolated bands in the northern and southern hemispheres (Figure 4c). Survival below the mixed layer, where $\mathrm{HOOH}$ concentrations are very low, would still be possible, but the contribution of this genus to global elemental cycling would be dramatically reduced. Caution must certainly be made when extrapolating the results of two strains in culture to model the impacts in natural communities. With that caveat in mind, this model suggests that Prochlorococcus owes its existence within its full permissive temperature range for growth, and consequently its full latitudinal range in the oceans, due to the magnitude of the $\mathrm{HOOH}$-degradation activity of the microbial community; were this magnitude to decrease, the range of Prochlorococcus would consequently shrink. Thus, with respect to temperature, the co-existing community functions to expand the realized niche of Prochlorococcus, effectively matching its physiologically constrained fundamental niche (Hutchinson, 1957).

\section{Conclusions}

Prochlorococcus is unusually sensitive to $\mathrm{HOOH}$, and this sensitivity is increased when growing at suboptimal temperatures. By alleviating oxidative stress, co-cultures of heterotrophs-serving as a 
proxy for the natural microbial community-effectively increase the temperature range at which Prochlorococcus can grow, and in more extreme scenarios slows the death kinetics, through the reduction of co-occurring oxidative stress. This study contributes to the growing body of evidence that facilitation, where one organism protects another from environmental stress, can expand the realized niche of microorganisms.

\section{Conflict of Interest}

The authors declare no conflict of interest.

\section{Acknowledgements}

This work was supported by grants from the NSF to ERZ (OCE-1030518), JJM (OCE-1540158) and ZIJ (OCE-1031064 and OCE 14-16665).

\section{References}

Allakhverdiev SI, Kreslavski VD, Klimov VV, Los DA, Carpentier R, Mohanty P. (2008). Heat stress: an overview of molecular responses in photosynthesis. Photosynth Res 98: 541-550.

Almeselmani M, Deshmukh PS, Sairam RK, Kushwaha SR, Singh TP. (2006). Protective role of antioxidant enzymes under high temperature stress. Plant Sci 171: 382-388.

Amin SA, Parker MS, Armbrust EV. (2012). Interactions between diatoms and bacteria. Microbiol Mol Biol Rev 76: $667-684$.

Behrenfeld MJ, Worthington K, Sherrell RM, Chavez FP, Strutton P, McPhaden M et al. (2006). Controls on tropical Pacific Ocean productivity revealed through nutrient stress diagnostics. Nature 442: 1025-1028.

Beliaev AS, Romine MF, Serres M, Bernstein HC, Linggi BE, Markillie LM et al. (2014). Inference of interactions in cyanobacterial-heterotrophic co-cultures via transcriptome sequencing. ISME J 8: 2243-2255.

Bertness MD, Callaway R. (1994). Positive Interactions in Communities. Trends Ecol Evol 9: 191-193.

Bertness MD, Leonard GH, Levine JM, Schmidt PR, Ingraham AO. (1999). Testing the relative contribution of positive and negative interactions in rocky intertidal communities. Ecology 80: 2711-2726.

Biller SJ, Berube PM, Berta-Thompson JW, Kelly L, Roggensack SE, Awad L et al. (2014). Genomes of diverse isolates of the marine cyanobacterium Prochlorococcus. Sci Data 1: 140034.

Brooker R, Kikvidze Z, Pugnaire FI, Callaway RM, Choler P, Lortie CJ et al. (2005). The importance of importance. Oikos 109: 63-70.

Brooker RW, Callaghan TV. (1998). The balance between positive and negative plant interactions and its relationship to environmental gradients: a model. Oikos 81: 196-207.

Bulleri F. (2009). Facilitation research in marine systems: state of the art, emerging patterns and insights for future developments. J Ecol 97: 1121-1130.
Callaway RM, Brooker RW, Choler P, Kikvidze Z, Lortie CJ, Michalet $\mathrm{R}$ et al. (2002). Positive interactions among alpine plants increase with stress. Nature 417: 844-848.

Chaloub R, Silva L, Rodrigues M, Dos Santos C. (2003). Phase transition of thylakoid membranes modulates photoinhibition in the cyanobacterium Anabaena siamensis. Photosynth Res 78: 143-152.

Chandler JW, Lin Y, Gainer PJ, Post AF, Johnson ZI, Zinser ER. (2016). Variable but persistent coexistence of Prochlorococcus ecotypes along temperature gradients in the ocean's surface mixed layer. Environ Microbiol Rep 8: 272-284.

Chen J, Shen J, Solem C, Jensen PR. (2013). Oxidative stress at high temperatures in Lactococcus lactis due to an insufficient supply of riboflavin. Appl Environ Microbiol 79: 6140-6147.

Chirac C, Casadevall E, Largeau C, Metzger P. (1985). Bacterial influence upon growth and hydrocarbon production of the green alga Botryococcus braunii. J Phycol 21: 380-387.

Coe A, Ghizzoni J, LeGault K, Biller S, Roggensack SE, Chisholm SW. (2016). Survival of Prochlorococcus in extended darkness. Limnol Oceanogr 61: 1375-1388.

Coleman ML, Chisholm SW. (2007). Code and context: Prochlorococcus as a model for cross-scale biology. Trends Microbiol 15: 398-407.

Cooper WJ, Saltzman ES, Zika RG. (1987). The contribution of rainwater to variability in surface ocean hydrogen peroxide. J Geophys Res 92: 2970-2980.

Croft MT, Lawrence AD, Raux-Deery E, Warren MJ, Smith AG. (2005). Algae acquire vitamin B12 through a symbiotic relationship with bacteria. Nature 438: 90-93.

Davidson JF, Whyte B, Bissinger PH, Schiestl RH. (1996). Oxidative stress is involved in heat-induced cell death in Saccharomyces cerevisiae. Proc Natl Acad Sci USA 93: $5116-5121$.

Dufresne A, Garczarek L, Partensky F. (2005). Accelerated evolution associated with genome reduction in a freeliving prokaryote. Genome Biol 6: R14.

Flombaum P, Gallegos JL, Gordillo RA, Rincon J, Zabala LL, Jiao N et al. (2013). Present and future global distributions of the marine cyanobacteria Prochlorococcus and Synechococcus. Proc Nat Acad Sci USA 110: 9824-9829.

Fu FX, Warner ME, Zhang YH, Feng YY, Hutchins DA. (2007). Effects of increased temperature and $\mathrm{CO}_{2}$ on photosynthesis, growth, and elemental ratios in marine Synechococcus and Prochlorococcus (Cyanobacteria). J Phycol 43: 485-496.

Geng H, Belas R. (2010). Molecular mechanisms underlying roseobacter-phytoplankton symbioses. Curr Opin Biotechnol 21: 332-338.

Giandomenico AR, Cerniglia GE, Biaglow JE, Stevens CW, Koch CJ. (1997). The importance of sodium pyruvate in assessing damage produced by hydrogen peroxide. Free Rad Biol Med 23: 426-434.

Gonzalez JM, Moran MA. (1997). Numerical dominance of $\alpha$ group of marine bacteria in the a-subclass of the class Proteobacteria in coastal seawater. Appl Environ Microbiol 63: 4237-4242.

Hanson AK, Tindale NW, Abdel-Moati MAR. (2001). An equatorial Pacific rain event: influence on the distribution of iron and hydrogen peroxide in surface waters. Mar Chem 75: 69-88. 
Hunken M, Harder J, Kirst GO. (2008). Epiphytic bacteria on the Antarctic ice diatom Amphiprora kufferathii Manguin cleave hydrogen peroxide produced during algal photosynthesis. Plant Biol (Stuttg) 10: $519-526$.

Hutchinson GE. (1957). Concluding remarks. Cold Spring Harb Symp Quant Biol 22: 415-427.

Johnson ZI. (2004). Description and application of the background irradiance gradient-single turnover fluorometer (BIG-STf). Mar Ecol-Prog Ser 283: 73-80.

Johnson ZI, Zinser ER, Coe A, McNulty NP, Malcolm E, Woodward S et al. (2006). Niche partitioning among Prochlorococcus ecotypes along ocean-scale environmental gradients. Science 311: 1737-1740.

Johnson ZI, Shyam R, Ritchie AE, Mioni C, Lance VP, Murray JW et al. (2010). The effect of iron- and lightlimitation on phytoplankton communities of deep chlorophyll maxima of the western Pacific Ocean. $J$ Mar Res 68: 283-308.

Kao KK, Fink MP. (2010). The biochemical basis for the anti-inflammatory and cytoprotective actions of ethyl pyruvate and related compounds. Biochem Pharmacol 80: $151-159$.

Keren N, Berg A, van Kan PJM, Levanon H, Ohad I. (1997). Mechanism of photosystem II photoinactivation and D1 protein degradation at low light: the role of back electron flow. Proc Nat Acad Sci USA 94: 1579-1584.

Keshtacher-Liebson E, Hadar Y, Chen Y. (1995). Oligotrophic bacteria enhance algal growth under irondeficient conditions. Appl Environ Microbiol 61: 2439-2441.

Kim JG, Park SJ, Sinninghe Damste JS, Schouten S, Rijpstra WI, Jung MY et al. (2016). Hydrogen peroxide detoxification is a key mechanism for growth of ammonia-oxidizing archaea. Proc Natl Acad Sci USA 113: 7888-7893.

Kocsy G, Galiba G, Brunold C. (2001). Role of glutathione in adaptation and signalling during chilling and cold acclimation in plants. Physiol Plant 113: 158-164.

Kojima K, Oshita M, Nanjo Y, Kasai K, Tozawa Y, Hayashi H et al. (2007). Oxidation of elongation factor $G$ inhibits the synthesis of the D1 protein of photosystem II. Mol Microbiol 65: 936-947.

Kranner I, Cram WJ, Zorn M, Wornik S, Yoshimura I, Stabentheiner E et al. (2005). Antioxidants and photoprotection in a lichen as compared with its isolated symbiotic partners. Proc Nat Acad Sci USA 102: 3141-3146.

Kulk G, de Vries P, van de Poll WH, Visser RJW, Buma AGJ. (2012). Temperature-dependent growth and photophysiology of prokaryotic and eukaryotic oceanic picophytoplankton. Mar Ecol Prog Ser 466: 43-55.

Lesser MP. (1996). Elevated temperatures and ultraviolet radiation cause oxidative stress and inhibit photosynthesis in symbiotic dinoflagellates. Limnol Oceanogr 41: 271-283.

Lin H, Kuzminov FI, Park J, Lee S, Falkowski PG, Gorbunov MY. (2016). The fate of photons absorbed by phtyoplankton in the global ocean. Science 351: 264-267.

Long LH, Halliwell B. (2009). Artefacts in cell culture: pyruvate as a scavenger of hydrogen peroxide generated by ascorbate or epigallocatechin gallate in cell culture media. Biochem Biophys Res Commun 388: 700-704.
Ma M, Eaton JW. (1992). Multicellular oxidant defense in unicellular organisms. Proc Natl Acad Sci USA 89: 7942-7928.

Maestre FT, Bautista S, Cortina J. (2003). Positive, negative, and net effects in grass-shrub interactions in Mediterranean semiarid grasslands. Ecology 84: 3186-3197.

Maestre FT, Cortina J. (2004). Do positive interactions increase with abiotic stress? A test from a semiarid steppe. Proc Biol Sci 271(Suppl 5): S331-S333.

Mella-Flores D, Six C, Ratin M, Partensky F, Boutte C, Le Corguille G et al. (2012). Prochlorococcus and Synechococcus have evolved different adaptive mechanisms to cope with light and UV stress. Frontiers Microbiol 3: 285.

Miller WL, Kester DR. (1994). Peroxide variations in the Sargasso Sea. Mar Chem 48: 17-29.

Mizunoe Y, Wai S, Takade A, Yoshida S. (1999). Restoration of culturability of starvation-stressed and lowtemperature-stressed Escherichia coli 0157 cells by using $\mathrm{H}_{2} \mathrm{O}_{2}$-degrading compounds. Arch Microbiol 172: $63-67$.

Morris JJ, Kirkegaard R, Szul MJ, Johnson ZI, Zinser ER. (2008). Facilitation of robust growth of Prochlorococcus colonies and dilute liquid cultures by 'helper' heterotrophic bacteria. Appl Environ Microbiol 74: 4530-4534.

Morris JJ, Johnson ZI, Szul MJ, Keller M, Zinser ER. (2011). Dependence of the cyanobacterium Prochlorococcus on hydrogen peroxide-scavenging microbes for growth at the ocean's surface. PLoS One 6: e16805.

Morris JJ, Lenski RE, Zinser ER. (2012). The Black Queen Hypothesis: evolution of dependencies through adaptive gene loss. mBio 3: e00036-00012.

Morris JJ, Zinser ER. (2013). Continuous hydrogen peroxide production by organic buffers in phytoplankton culture media. J Phycol 49: 1223-1228.

Morris JJ, Papoulis SE, Lenski RE. (2014). Coexistence of evolving bacteria stabilized by a shared Black Queen function. Evolution 68: 2960-2971.

Morris JJ, Johnson ZI, Zinser ER. (2016). Diel regulation of hydrogen peroxide defenses by open ocean communities. J Plankton Res 38: 1103-1114.

Mouget JL, Dakhama A, Lavoie MC, de la Noue J. (1995). Algal growth enhancement by bacteria: Is consumption of photosynthetic oxygen involved? FEMS Microbiol Ecol 18: 35-44.

Murata N, Takahashi S, Nishiyama Y, Allakhverdiev SI. (2007). Photoinhibition of photosystem II under environmental stress. BBA-Bioenergetics 1767: 414-421.

Murphy CD, Roodvoets MS, Austen EJ, Dolan A, Barnett A, Campbell DA. (2017). Photoinactivation of Photosystem II in Prochlorococcus and Synechococcus. PLoS One 12: e0168991.

Neale PJ, Thomas BC. (2017). Inhibition by ultraviolet and photosynthetically available radiation lowers model estimates of depth-integrated picophytoplankton photosynthesis: global predictions for Prochlorococcus and Synechococcus. Glob Chang Biol 23: 293-306.

Nishiyama Y, Yamamoto H, Allakhverdiev SI, Inaba M, Yokota A, Murata N. (2001). Oxidative stress inhibits the repair of photodamage to the photosynthetic machinery. EMBO J 20: 5587-5594.

Nishiyama Y, Allakhverdiev SI, Murata N. (2006). A new paradigm for the action of reactive oxygen species in 
the photoinhibition of photosystem II. Biochim Biophys Acta 1757: 742-749.

Partensky F, Hess WR, Vaulot D. (1999). Prochlorococcus, a marine photosynthetic prokaryote of global significance. Microbiol Mol Biol Res 63: 106-127.

Redman RS, Sheehan KB, Stout RG, Rodriguez RJ, Henson JM. (2002). Thermotolerance generated by plant/fungal symbiosis. Science 298: 1581.

Richier S, Furla P, Plantivaux A, Merle PL, Allemand D. (2005). Symbiosis-induced adaptation to oxidative stress. J Exp Biol 208: 277-285.

Rocap G, Distel DL, Waterbury JB, Chisholm SW. (2002). Resolution of Prochlorococcus and Synechococcus ecotypes by using 16S-23S ribosomal DNA internal transcribed spacer sequences. Appl Environ Microbiol 68: 1180-1191.

Ryan-Keogh TJ, Macey AI, Nielsdóttir MC, Lucas MI, Steigenberger SS, Stinchcombe MC et al. (2013). Spatial and temporal development of phytoplankton iron stress in relation to bloom dynamics in the highlatitude North Atlantic Ocean. Limnol Oceanogr 58: 533-545.

Scanlan DJ, Ostrowski M, Mazard S, Dufresne A, Garczarek L, Hess WR et al. (2009). Ecological genomics of marine Picocyanobacteria. Microbiol Molec Biol Rev 73: 249-299.

Schiefer GE, Caldwell DE. (1982). Synergistic interaction between Anabaena and Zoogloea spp. in carbon dioxide-limited continuous cultures. Appl Environ Microbiol 44: 84-87.

Six C, Finkel ZV, Irwin AJ, Campbell DA. (2007). Light variability illuminates niche partitioning among marine picocyanobacteria. PLoS One 2: e1341.

Smirnova GV, Muzyka NG, Oktyabrsky ON. (2007). Enhanced resistance to peroxide stress in Escherichia coli grown outside their niche temperatures. J Thermal Biol 32: 321-327.

Strehl B, Holtzendorff J, Partensky F, Hess WR. (1999). A small and compact genome in the marine cyanobacterium Prochlorococcus marinus CCMP 1375: lack of an intron in the gene for tRNA(Leu) ${ }^{\mathrm{UAA}}$ and a single copy of the rRNA operon. FEMS Microbiol Lett 181: 261-266.

Takahashi K, Onodera J, Katsurada Y. (2009). Relationship between time-series diatom fluxes in the central and western equatorial Pacific and ENSO-associated migrations of the Western Pacific Warm Pool. Deep Sea Res I 56: 1298-1318.
Thomas DJ, Thomas JB, Prier SD, Nasso NE, Herbert SK. (1999). Iron superoxide dismutase protects against chilling damage in the cyanobacterium Synechococcus species PCC7942. Plant Physiol 120: 275-282.

Tripp HJ, Kitner JB, Schwalbach MS, Dacey JWH, Wilhelm LJ, Giovannoni SJ. (2008). SAR11 marine bacteria require exogenous reduced sulphur for growth. Nature 452: 741-744.

Troxell B, Zhang JJ, Bourret TJ, Zeng MY, Blum J, Gherardini F et al. (2014). Pyruvate protects pathogenic spirochetes from $\mathrm{H}_{2} \mathrm{O}_{2}$ killing. PLoS One 9: e84625.

Vass I, Styring S, Hundal T, Koivuniemi A, Aro EM, Andersson B. (1992). Reversible and irreversible intermediates during photoinhibition of photosystem II: stable reduced $\mathrm{Q}_{\mathrm{A}}$ species promote chlorophyll triplet formation. Proc Nat Acad Sci USA 89: 1408-1412.

Vass I. (2011). Role of charge recombination processes in photodamage and photoprotection of the photosystem II complex. Physiol Plant 142: 6-16.

Waterbury JB, Willey JM. (1988). Isolation and growth of marine planktonic cyanobacteria. Methods Enzymol 167: 100-105.

Wilhelm SW, King AL, Twining BS, LeCleir GR, DeBruyn JM, Strzepek RF et al. (2013). Elemental quotas and physiology of a southwestern Pacific Ocean plankton community as a function of iron availability. Aquatic Microbial Ecology 68: 185-194.

Wise RR. (1995). Chilling-enhanced photooxidation: the production, action and study of reactive oxygen species produced during chilling in the light. Photosynth Res 45: 79-97.

Xie B, Bishop S, Stessman D, Wright D, Spalding $\mathrm{MH}$, Halverson LJ. (2013). Chlamydomonas reinhardtii thermal tolerance enhancement mediated by a mutualistic interaction with vitamin $\mathrm{B}_{12}$-producing bacteria. ISME J 7: 1544-1555.

Yuan J, Shiller AM. (2001). The distribution of hydrogen peroxide in the southern and central Atlantic ocean. Deep Sea Res II 48: 2947-2970.

Zwirglmaier K, Jardillier L, Ostrowski M, Mazard S, Garczarek L, Vaulot D et al. (2008). Global phylogeography of marine Synechococcus and Prochlorococcus lineages reveals a distinct partitioning of lineages among oceanic biomes. Environ Microbiol 10: 147-161.

Supplementary Information accompanies this paper on The ISME Journal website (http://www.nature.com/ismej) 